\title{
Effect of spinal surgery on lung function in Duchenne muscular dystrophy
}

\author{
J Declan Kennedy, Alan J Staples, Philip D Brook, David W Parsons, \\ Andrew D Sutherland, A James Martin, Leon M Stern, Bruce K Foster
}

\begin{abstract}
Background - The effect on subsequent respiratory function of spinal stabilisation for scoliosis in Duchenne muscular dystrophy is unclear. In order to clarify this clinical problem, changes in the forced vital capacity of a group of children with Duchenne muscular dystrophy who had undergone spinal surgery were measured and compared with a group of children with Duchenne muscular dystrophy who had not had surgery.
\end{abstract}

Methods - In this retrospective study 17 boys with Duchenne muscular dystrophy who underwent spinal stabilisation at a mean age of 14.9 years (surgical group) were compared with 21 boys with Duchenne muscular dystrophy who had not had surgery (non-surgical group). The mean (SD) Cobb angle of the surgical group at 14.9 years was $57(16.4)^{\circ}$, and of the non-surgical group at 15 years was 45 (29.9) ${ }^{\circ}$. Forced vital capacity expressed as percentage predicted (\% FVC) was measured in total over a seven year period in the surgical group and over 6.5 years in the non-surgical group, and regression equations were calculated. Survival curves for both groups were also constructed.

Results - No difference was found between spinal stabilisation (surgical group) and the non-surgical group in the rate of deterioration of \% FVC which was 3-5\% per year. There was no difference in survival in either group.

Conclusions - Spinal stabilisation in Duchenne muscular dystrophy does not alter the decline in pulmonary function, nor does it improve survival.

(Thorax 1995;50:1173-1178)

Keywords: Duchenne muscular dystrophy; forced vital capacity; survival analysis.

Duchenne muscular dystrophy is the commonest form of muscular dystrophy, affecting 1:3500 live male births. ${ }^{1}$ Significant advances in the understanding of the molecular basis of the condition have been made in recent years with the isolation of the responsible gene on the $\mathrm{Xp} 21$ region of the $\mathrm{X}$ chromosome. ${ }^{2}$ One of the gene products, dystrophin, is an integral part of the skeletal muscle cell membrane where it forms a complex with glycoprotein. If this complex is deficient, as in Duchenne muscular dystrophy, calcium influx into the cell results, leading to muscle degeneration and necrosis. ${ }^{3}$
Despite these advances in the understanding of Duchenne muscular dystrophy, with their major implications for prenatal diagnosis, the life expectancy of affected children has not altered greatly since Gower's original series of 1879. ${ }^{4}$ Respiratory failure is the major cause of death in approximately $90 \%$ of children with Duchenne muscular dystrophy, with $10 \%$ attributed to cardiac causes. ${ }^{5}$ Respiratory failure is the result of several interacting processes which include intercostal muscle weakness, reduced lung and chest wall compliance, an ineffective cough, central and obstructive hypoxaemia, and scoliosis. ${ }^{6-8}$

Scoliosis develops in nearly all children with Duchenne muscular dystrophy, ${ }^{7}$ usually within a few years of becoming wheelchair bound. ${ }^{1}$ Progression of the curve may further impair the already diminishing pulmonary function by reducing the mechanical efficiency of the chest wall musculature. ${ }^{9}$

Whilst it is clear that surgical correction of the curve improves nursing care and quality of life by allowing a more comfortable wheelchair posture and a reduction in back pain, ${ }^{1011}$ its effect on pulmonary function and life expectancy is controversial. Several studies have shown no change in the decline in pulmonary function following curve correction, ${ }^{1012}$ while Galasko et $a l^{13}$ recently reported that stabilisation of pulmonary function was achieved for up to 36 months after spinal surgery and led to improved survival. Given this disagreement in published findings and their obvious implication, this study was therefore undertaken to evaluate the effect of spinal surgery on the decline in forced vital capacity (FVC) in a group of children with Duchenne muscular dystrophy. These children were compared with affected children who had not had surgery.

\section{Methods}

All patients attended the Orthopaedic Clinic at the Women's and Children's Hospital or the Muscular Dystrophy Clinic at the Regency Park Centre for Young Disabled, Adelaide, South Australia. The diagnosis of Duchenne muscular dystrophy was made on the basis of family history, raised muscle enzyme levels, electrophysiological studies, and muscle biopsy samples. Between 1960 and 1993 a total of 58 patients with Duchenne muscular dystrophy were reviewed.

\section{SURGICAL GROUP}

During the 10 year period 1983-93, 17 children with Duchenne muscular dystrophy underwent 
segmental spinal instrumentation. In the first 10 cases the Luque rod technique alone was used, and in the remaining seven the Galveston technique of pelvic fixation and cross locking was also utilised.

\section{NON-SURGICAL GROUP}

Twenty one children were allocated to the nonsurgical Duchenne muscular dystrophy group as they had not had spinal surgery and had more than one year of pulmonary follow up and three or more pulmonary function tests. The non-surgical group comprised four patients whose parents refused surgery, seven whose respiratory status was considered to pose a significant operative risk, and 10 patients whose curve severity at most recent review did not require correction.

The periods of evaluation for the study group were divided into before and after surgical stabilisation (mean age of surgery 14.96 years) and before and after 15 years of age in the non-surgical group. Randomisation was not achieved as surgery was undertaken for varying indications - that is, severity of back pain or ease of nursing - rather than the influence of spinal stabilisation on lung function per se.

Forced vital capacity (FVC) was measured using an Ohio 842 spirometer and Jaeger Masterlab system. All measurements adhered to standards established by the Snowbird Conference $^{14}$ and the GAP Conference on Standardisation of Lung Function Testing in Children. ${ }^{15}$ Percentage predicted FVC (\% FVC) values were recorded using armspan measurements to calculate height. ${ }^{16}$ The predicted value equations of Zapletal ${ }^{17}$ were used for children aged 6-18 years and those of $\mathrm{Crapo}^{18}$ for those patients older than 18 years.

Curve severity was assessed by erect posteroanterior (or sitting anteroposterior if not able to stand) and lateral spinal radiographs, using the method of Cobb. ${ }^{19}$ All measurements were performed by two of the authors (PDB, BKF).

Each patient's percentage predicted FVC was individually plotted against age (not shown) and showed that the decline in \% FVC occurred at varying ages in the individual patients. This therefore suggested that two factors needed to be considered: the age of the patient and the level of \% FVC at that age. To allow a valid comparison of the rate of decline in \% FVC between surgical and non-surgical patients the effect of age per se was therefore removed by selecting the time before and after surgery as the independent variables in the regression analyses. If this is not done, and \% FVC is regressed against age for each group, bias may be introduced because the influence of multiple different times of onset of \% FVC decline in individual patients may significantly alter the true slope of the line - that is, multicolinearity bias. This bias is corrected by transforming the data of both the surgical and nonsurgical groups to a common set of axes (\% FVC versus time where time $=$ age minus the mean age of surgery). This allows a common starting point - that is, time of surgery - to compare both surgical and non-surgical groups. Using these two common axes - the \% FVC $y$ axis and the time $x$ axis - four regression lines were constructed: (1) the total surgical group; (2) the total non-surgical group. The surgical group was then subdivided into (3) the preoperative group and (4) the postoperative group. This latter subdivision into separate preoperative and postoperative surgical groups allowed the comparison of both of these regression line predictions of \% FVC at time of surgery - that is, same constant term. This is an important check as the maximum errors in regression lines occur at the extremes of the data range; the close similarity of values at this point of intersection attest to the absence of bias.

\section{STATISTICAL ANALYSIS}

Surgical group

As outlined above, three separate linear regression estimates were calculated for (1) preoperative, (2) postoperative, and (3) total (preoperative and postoperative) patients using the linear model:

$\% \mathrm{FVC}=(\% \mathrm{FVC}$ at time of surgery $)+($ rate of decline in \% FVC/year) $\times$ (time)

where time equals the number of years before or after surgery. Preoperative years have negative values, time of surgery is zero, and postoperative years have positive values.

\section{Non-surgical group}

In this group age was transformed to a new axis - that is, time - by means of the transformation time $=$ age -14.96 (where $14.96=$ the mean age of surgery in the surgical group). Thus, the regression estimate for the non-surgical group became:

$\% \mathrm{FVC}=(\% \mathrm{FVC}$ at mean age of 14.96$)+($ rate of decline in \% FVC/year) $\times$ (time).

Standard deviations of the estimates and Student $t$ values are shown in table 2. The survival curve data were analysed using the MannWhitney $U$ test. A statistical power of $\beta=0 \cdot 80$ was achieved at an $\alpha=0.05$ significance level.

\section{Results}

COMPARABILITY OF STUDY GROUPS

Respiratory evaluation (table 1)

No difference was found in the duration of respiratory evaluation or in the number of pulmonary function tests in either group. Because the mean age at surgery was $\mathbf{1 4 . 9 6}$ years, the assessment of the non-surgical group was divided into two sections - above and below 15 years of age - to allow a valid comparison of respiratory outcomes.

\section{Orthopaedic evaluation}

Surgical group: The mean preoperative Cobb angle for the 17 surgical patients was $57(16 \cdot 4)^{\circ}$. 
Table 1 Mean (SD) data of patients in the surgical (spinal instrumentation) and nonsurgical groups

\begin{tabular}{|c|c|c|c|}
\hline & $\begin{array}{l}\text { Spinal } \\
\text { stabilisation } \\
(n=17)\end{array}$ & & $\begin{array}{l}\text { Non-surgical } \\
(n=21)\end{array}$ \\
\hline $\begin{array}{l}\text { Pulmonary evaluation period (ye } \\
\text { Total } \\
\text { Preoperative } \\
\text { Postoperative }\end{array}$ & $\begin{array}{l}7.08(3.49) \\
4.63(3.33) \\
2.44(1.58)\end{array}$ & $\begin{array}{l}\text { Below } 15 \text { years age } \\
\text { Above } 15 \text { years age }\end{array}$ & $\begin{array}{l}6 \cdot 51(3.62) \\
3 \cdot 74(3.08) \\
2 \cdot 77(2 \cdot 60)\end{array}$ \\
\hline $\begin{array}{l}\text { No. pulmonary function tests } \\
\text { Total } \\
\text { Preoperative } \\
\text { Postoperative }\end{array}$ & $\begin{array}{r}11 \cdot 25(4 \cdot 89) \\
7 \cdot 06(4 \cdot 82) \\
4 \cdot 19(2 \cdot 56)\end{array}$ & $\begin{array}{l}\text { Below } 15 \text { years age } \\
\text { Above } 15 \text { years age }\end{array}$ & $\begin{array}{r}10 \cdot 14(7 \cdot 40) \\
6 \cdot 56(4 \cdot 94) \\
3.57(3.30)\end{array}$ \\
\hline $\begin{array}{l}\text { No. patients dead } \\
\text { Age at death (years) } \\
\text { Postoperative survival (years) }\end{array}$ & $\begin{array}{l}10 \\
18 \cdot 22(2 \cdot 65) \\
3 \cdot 80(2 \cdot 10)\end{array}$ & & $\begin{array}{l}11 \\
19 \cdot 51(3 \cdot 22) \\
\text { NA }\end{array}$ \\
\hline
\end{tabular}

$\mathrm{NA}=$ not applicable

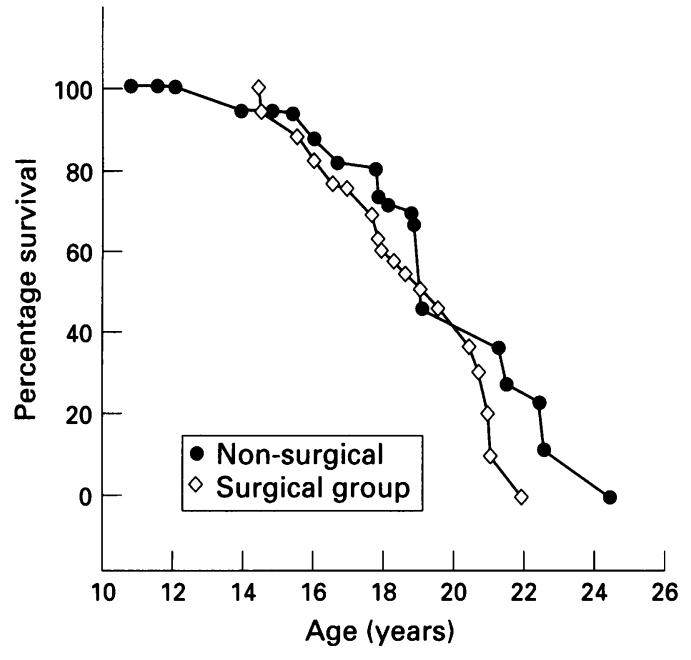

The immediate postoperative mean Cobb angle was $22(9 \cdot 1)^{\circ}$, a mean correction of $59(16 \cdot 7) \%$. At the most recent orthopaedic follow up a mean of $2.4(1.6)$ years after surgery the Cobb angle was $24(6 \cdot 7)^{\circ}$. The mean age at time of operation was $14.9(2 \cdot 1)$ years.

Non-surgical group: In this group at age 15 years (excluding four children who had not attained this age), the mean Cobb angle was $45 \cdot 4(29 \cdot 0)^{\circ}$. Of the four children aged between 10 and 15 years, three had a curve of $20^{\circ}$ or greater $\left(20^{\circ}, 20^{\circ}, 60^{\circ}\right)$ and one had a curve of $10^{\circ}$. In the remaining 17 children four had curves of $10-15^{\circ}$ while 13 had curves of $18-100^{\circ}$ when aged 15 years. The mean length of orthopaedic follow up in the group (in those more than 15 years old) was $2 \cdot 7(2 \cdot 6)$ years, and their Cobb angle at most recent assessment was $47.9(32 \cdot 5)^{\circ}$.

COMPARISON OF CURVE SEVERITY BETWEEN SURGICAL AND NON-SURGICAL GROUPS

No significant difference in Cobb angle was found between either group at age 15 years. The non-surgical group contained a wider range of curves than the surgical group, as the former was composed of some children in whom surgery was declined because their respiratory status was considered to pose a significant operative risk, and other children whose curves did not yet require correction.

SITE OF CURVE

In the surgical group three children had double curves, one had a thoracic curve, and $13 \mathrm{had}$ thoracolumbar curves. The non-surgical group included one child with a double curve, three with thoracic curves, and 17 with thoracolumbar curves. Percentage FVC was not correlated with the Cobb angle in either the surgical or non-surgical group $(r=0.39, \mathrm{p}=$ $\mathrm{NS}$, and $r=0 \cdot 39, \mathrm{p}=\mathrm{NS}$, respectively).

GROUP SURVIVAL AND SURVIVAL CURVES

Ten of the 17 surgical patients had died at the time of analysis, and in these patients the mean postoperative survival was 3.8 years (range 0.9 $6 \cdot 8)$; the mean age at death was 18.2 years (range 14.5-21) (table 1).

Of the non-surgical patients 11 had died and 10 were alive at time of analysis. In this group
Figure 1 Survival curves for surgical and non-surgical patient groups.

the mean age at death was 19.5 years (range 12.9-24.4) (table 1).

Survival curves for the surgical and nonsurgical patient groups are shown in fig 1 . Although the survival curves suggest that nonsurgical patients live longer than surgical patients, there is no statistical difference between these curves.

\section{FALL IN \% FVC WITH TIME}

In the surgical group the similarity of the values of $\%$ FVC at the time of surgery of both the preoperative regression line $(42 \cdot 8 \%)$ and the postoperative regression line $(42 \cdot 6 \%)$ indicates that these regression estimates form a continuum and display no suggestion of bias. The estimates of both total surgical and total nonsurgical regression lines were also not statistically different at the time of surgery. No significant differences were found between the following regression lines for \% FVC decline versus time: (1) preoperative versus postoperative surgical groups; (2) preoperative and postoperative surgical groups versus total surgical group; (3) preoperative and postoperative surgical groups versus non-surgical groups above and below 15 years of age; and (4) total surgical group versus total non-surgical group.

\section{RATES OF DETERIORATION}

In the non-surgical group the rate of decline in $\%$ FVC was $3 \cdot 22 \%$ per year. In the surgical group the rate of deterioration - that is, the slope in the three surgical group regression equations ( $\%$ FVC fall per year $=4 \cdot 12 \%$, $5 \cdot 34 \%$, and $4.27 \%$ for preoperative, postoperative, and total surgical group patients, respectively) - indicate a mean decrease of $4.6 \%$ in \% FVC per annum throughout life. Although the postoperative value of $5 \cdot 34 \%$ suggests a more rapid decline in \% FVC when patients, there was no statistical difference between these rates of deterioration (fig $2 \mathrm{~A}$ and $2 B$; regression equations are given in table 2 ). compared with non-surgical and preoperative 


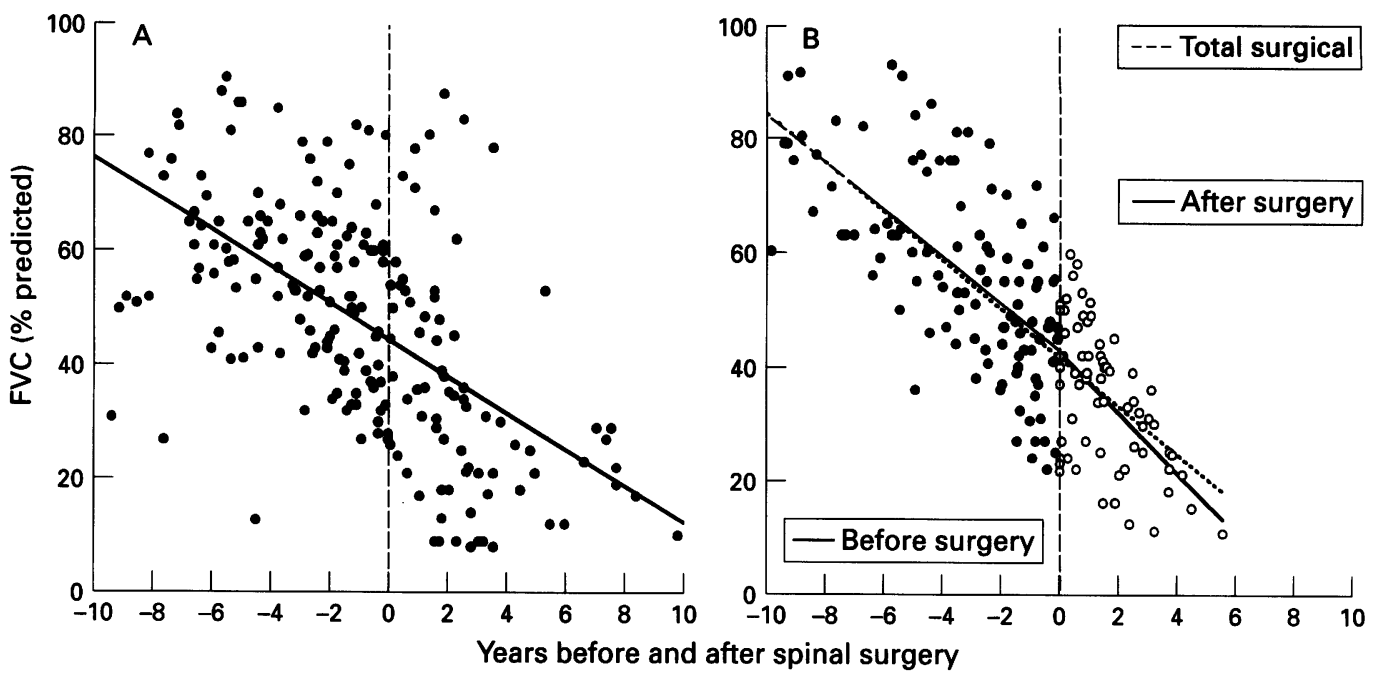

Figure 2 Regression curves for $(A)$ non-surgical and (B) surgical patient groups. Equations are given in table 2.

\section{Discussion}

This study shows that spinal instrumentation does not alter the progressive decline in pulmonary function in this group of children with Duchenne muscular dystrophy. The study was not randomised, but this caveat also applies to previously published studies on lung function in the area. ${ }^{10121320}$ A controlled trial of the effect of spinal stabilisation on lung function is unlikely to be achieved in this group of patients, as the indications for surgery include the subjective clinical problems of back pain and seating difficulties. The results of this study should therefore be viewed with this limitation in mind.

Previous studies have evaluated \% FVC versus the age of the patient with Duchenne muscular dystrophy, ${ }^{1021}$ but an inherent problem in the analysis of the rate of decline in \% FVC in Duchenne muscular dystrophy is that patients vary both in the age of onset of the \% FVC decline and in the time of death. The regression of \% FVC versus age, though commonly performed, therefore risks the bias of multicolinearity. Elapsed time, rather than age, is therefore used so that a valid comparison can be made between the surgical and nonsurgical groups. In the present study no significant difference was found in the rate of decline in \% FVC between the surgical and non-surgical groups or between the preoperative and postoperative periods. In addition, at the time of surgery (age 14.96 years) no difference was found between the \% FVC of the surgical and non-surgical groups. This implies that, from a respiratory viewpoint, both groups were highly comparable throughout the period of evaluation.

Table 2 Regression equations

\begin{tabular}{llllllr}
\hline & $b_{0}$ & $S D$ & $t$ value & $b_{1}$ & $S D$ & $t$ value \\
\hline Surgical & & & & & & \\
$\quad$ Preoperative & 42.88 & 1.93 & 22.28 & -4.12 & 0.46 & 9.00 \\
Postoperative & 42.63 & 1.92 & 22.22 & -5.35 & 0.95 & 5.64 \\
$\quad$ Total surgical & 41.62 & 0.97 & 43.01 & -4.27 & 0.27 & 16.22 \\
Non-surgical & 44.44 & 4.14 & 21.44 & -3.22 & 0.30 & 10.66 \\
\hline
\end{tabular}

Regression model: $\% F V C=b_{0}+b_{1} \times($ time $)$
EFFECT OF CURVE CORRECTION ON LUNG FUNCTION

The role of spinal surgery in stabilising or improving the gradual decline in pulmonary function in patients with Duchenne muscular dystrophy is contentious. From a theoretical viewpoint, correction of the spinal curve may increase the mechanical advantage of the respiratory muscles by improving length-tension characteristics. The important consideration, however, is that the curve needs to involve the thoracic spine for this theoretical benefit to occur. In this study $85 \%$ of the curves were thoracolumbar in the non-surgical group and $76 \%$ were thoracolumbar in the surgical group. It has previously been shown in idiopathic scoliosis that, unless the curve involves the thoracic vertebrae, respiratory impairment is not significant $^{223}$; one would not therefore anticipate postoperative improvement in respiratory function in non-thoracic curves. Even in idiopathic thoracic scoliosis there is disagreement in the literature on the effect of spinal surgery on subsequent pulmonary function, with some authors reporting improvement $^{24-26}$ while others have reported either deterioration or no significant change. ${ }^{27-29}$

\section{IMPORTANCE OF SITE OF CURVE}

In most of the studies that have evaluated the role of spinal surgery on pulmonary function in Duchenne muscular dystrophy, little detail has been given of the site of the curve. ${ }^{10121320}$ However, most patients with Duchenne muscular dystrophy have low thoracic or lumbar curves. ${ }^{1}$ Smith et $a l^{7}$ reported thoracic curves in only $10 \%$ of their series of 51 patients with Duchenne muscular dystrophy, while in the study of 27 patients with Duchenne muscular dystrophy by Shapiro et $a l^{11}$ all the curves except three involved the thoracolumbar spine. Kurz et $a l^{21}$ found that neither the thoracolumbar nor lumbar curve angle was a statistically significant predictor of pulmonary function in their series of 25 patients.

In idiopathic scoliosis it was shown by Flagstad and Kollman ${ }^{22}$ that there was an inverse 
relationship between thoracic curve angle and forced vital capacity. This finding has since been verified by many studies. ${ }^{30-32}$ This inverse relationship has not been consistently found in Duchenne muscular dystrophy, with some, ${ }^{721}$ but not all, ${ }^{12}$ authors reporting a significant inverse relationship. This study supports the latter view. It is clear that in paralytic thoracic scoliosis both muscle weakness and chest wall deformity will contribute to lung volume reduction and the dominant factor is likely to be the degree of muscle weakness. Surgical correction of the curve is therefore unlikely to alter respiratory status to a significant extent.

\section{EFFECT OF SPINAL SURGERY ON LUNG} FUNCTION

Considerable debate in the literature has centred on the effect of spinal surgery in Duchenne muscular dystrophy on subsequent pulmonary function. ${ }^{121320}$ Galasko et al $^{13}$ recently reported that spinal stabilisation in Duchenne muscular dystrophy can prevent the progression of scoliosis for at least five years, stabilise pulmonary function for 36 months, and improve survival. On the basis of their findings, the authors suggested that it would be unethical to randomise any future studies on spinal stabilisation in this condition. Analysis of their preoperative data is difficult as the results of FVC are given as absolute values rather than percentage predicted, and there is no reported comparison of the rate of deterioration in FVC between non-surgical and surgical groups.

Jenkins et $a l^{20}$ have shown that, although absolute vital capacity (VC) increased with age in Duchenne muscular dystrophy, VC expressed as percentage predicted progressively declined. Analysis of the postoperative data in the study of Galasko et $a l^{13}$ is also difficult for several reasons. Follow up was apparently incomplete: by 36 months only 18 out of the original 32 patients in the preoperative group had their pulmonary function recorded. Five patients were operated on too recently to provide data, but the survival data provided suggest that approximately $90 \%$ of the preoperative group (29 patients) were alive at 36 months after surgery. In addition, as in the preoperative assessment, the results of VC were given in absolute units rather than percentage predicted. Peak expiratory flow rate (PEF) is reported to have increased significantly in those who had undergone spinal surgery. ${ }^{13}$

However, peak expiratory flow rates are not the optimum method of monitoring lung function in children with neuromuscular disease. In these children there is an interplay of several physiological forces during PEF measurement with differing effects - impaired force and velocity of expiratory muscle contraction due to muscle weakness with resultant reduction in expiratory flow, a reduction in the maximum inspiratory lung volume with a subsequent fall in lung static recoil pressure and therefore peak flow, and a rise in lung static recoil pressure per unit lung volume secondary to a decrease in lung compliance. The latter effect will increase driving pressure and peak flow rate. ${ }^{33} 34$ In the effort independent portion of the expiratory flow volume loop maximum flow rates are obtainable over much of the vital capacity. ${ }^{6}$ For these reasons, inspiratory measurements may be a more sensitive indicator of deteriorating respiratory muscle strength. The inspiratory flow generated will depend on the ability of the inspiratory muscles to lower pleural pressure, and the increase in lung compliance will reduce inspiratory flow rather than help as on the expiratory limb. ${ }^{34}$ Inspiratory capacity measurement is also potentially useful as it represents the power of the inspiratory muscles to overcome the elastic recoil pressure of chest wall and lung. ${ }^{6}$

\section{COMPARISON WITH OTHER STUDIES}

The findings of the majority of studies are not in agreement with those of Galasko et $a l^{13}$ and report no significant improvement or stabilisation in lung volumes after spinal surgery in patients with Duchenne muscular dystrophy. ${ }^{1012}$ The results of the present study support this view, and the strength of this study lies in two major factors. Firstly, the close comparability of pulmonary function in both surgical and non-surgical groups during the preoperative evaluation period allows precise comparisons of the effect of surgical intervention. Secondly, the frequency of pulmonary function testing in both preoperative and postoperative periods enables the rate of deterioration of pulmonary function in both patient groups to be clearly defined.

The rate of deterioration of \% FVC was approximately $3-5 \%$ per year in this study. This is in keeping with the findings of Shapiro et al. ${ }^{11}$ Unlike the report of Galasko et al, ${ }^{13}$ no difference in survival rates between the surgical and non-surgical groups was noted in this study and the mean age of death was similar to that of Smith et al. ${ }^{7}$

In this study (fig 1) it may appear as if survival is better in the non-surgical group when the curves are compared at their extremes. However, no statistical difference in survival was found between the two groups. The apparent improved survival in the non-surgical group is due to the imprecision inherent in the calculation of the two curves when, in the older age groups, the sample size is relatively small and survivors are few.

In conclusion, there is general agreement that spinal stabilisation is important in improving the quality of life and facilitating nursing care in children with Duchenne muscular dystrophy. ${ }^{35-37}$ However, spinal surgery should be undertaken before respiratory function is so significantly compromised that the procedure poses a significant anaesthetic risk to the patient. Many authorities believe that surgery should be offered to children whose curve has reached $20^{\circ}$ or who cannot walk ${ }^{713}$ because, if surgery is delayed until the curve is greater than $35^{\circ}$, respiratory function is often significantly compromised. The authors believe that, if there are good quality of life reasons for considering surgery - for example, back pain, ease of nursing - those patients with FVC greater than 
$20 \%$ predicted should be assessed, provided postoperative respiratory support and intensive monitoring facilities are available. With the recent development and use of nocturnal supportive ventilatory systems, long term survival should improve ${ }^{38}$ and it may be possible in the future to offer surgery to those whose FVC is less than $20 \%$ predicted. However, this study shows that spinal stabilisation does not alter the inevitable decline in lung function.

Thanks are due to Paul Rogers and Lisa Edwards for assistance with pulmonary function testing, and to Pam Roberts for manuscript preparation.

1 Shapiro F, Specht L. Current concepts review - the diagnosis and orthopaedic treatment of inherited muscular diseases of childhood. 7 Bone foint Surg 1993;75-A:439-54.

2 Hoffman EP, Kunkel LM. Dystrophin abnormalities in Duchenne/Becker muscular dystrophy. Neuron 1989;2: 1019-29.

3 Emery AEH. Duchenne muscular dystrophy. 2nd ed. Oxford: Oxford University Press, 1993:190-208.

4 Emery AEH. Duchenne muscular dystrophy. 2nd ed. Oxford: Oxford University Press, 1993:40-41.

5 Rideau Y, Gatin G, Bach J, Gines G. Prolongation of life in Duchenne's muscular dystrophy. Acta Neurol (Napoli) 1983;5:118-24.

6 Smith PEM, Calverley PMA, Edwards RHT, Evans GA, Campbell EJM. Practical problems in the respiratory care of patients with muscular dystrophy. $N$ Engl $₹$ Med 1987; of patients with

7 Smith AD, Koreska J, Moseley CF. Progression of scoliosis in Duchenne muscular dystrophy. F Bone foint Surg 1989; 71-A:1066-74

8 Khan Y, Heckmatt JZ. Obstructive apnoeas in Duchenne muscular dystrophy. Thorax 1994;49:157-61.

9 Roussos C. Ventilatory failure and respiratory muscles. In: Roussos C Macklem PT, eds. The thorax. New York: Marcel Dekker, 1985:1253-79.

10 Miller RG, Chalmers AC, Dao H, Filler-Katz A, Holman $\mathrm{D}$, Bost $\mathrm{F}$. The effect of spine fusion on respiratory
function in Duchenne muscular dystrophy. Neurology 1991;41:38-40.

11 Shapiro F, Sethna N, Colan S, Wohl ME, Specht L. Spinal fusion in Duchenne muscular dystrophy: a multidisciplinary approach. Muscle Nerve 1992;15:604-14

12 Miller F, Moseley CF, Koreska J, Levison H. Pulmonary function and scoliosis in Duchenne dystrophy. $f$ Pediatr Orthop 1988;8:133-7.

13 Galasko CSB, Delaney C, Morris P. Spinal stabilisation in Duchenne muscular dystrophy. F Bone foint Surg 1992; 74-B:210-4.

14 ATS Statement - Snowbird Workshop on standardization of spirometry. Am Rev Respir Dis 1979;119:831-8.

15 Taussig LM, Chernick V, Wood R, Farrell P, Mellins RD. Standardization of lung function testing in children. Proceedings and recommendations of the GAP Conference Committee, Cystic Fibrosis Foundation. $\mathcal{f}$ Pediatr 1980 97:668-76.

16 Hepper NGG, Black LF, Fowler WS. Relationships of lung volume to height and arm span in normal subjects and in patients with spinal deformity. Am Rev Respir Dis 1965; patients with
17 Zapletal A, Motoyama EK, Van de Woestijne, Hunt VR, Bouhuys A. Maximum expiratory flow volume curves and airway conductance in children and adolescents. $\mathcal{F} A p p l$ airway conductance in chil

18 Crapo RO, Morris AH, Gardner RM. Reference spirometric values using techniques and equipment that meet ATS recommendations. Am Rev Respir Dis 1981;123:659-64.

19 Cobb JR. Outline for the study of scoliosis. Instructiona Course Lectures. Am Acad Orthop Surg 1948;5:261-75.

20 Jenkins JG, Bohn D, Edmonds JF, Levison H, Barker GA Evaluation of pulmonary function in muscular dystrophy patients requiring spinal surgery. Crit Care Med 1982;10: 645-9.

21 Kurz LT, Mubarak SJ, Schultz P, Park SM, Leach J. Correlation of scoliosis and pulmonary function in Duchenn relation of scoliosis and pulmonary function in Duchent

22 Flagstad AE, Kollman S. Vital capacity and muscle study in one hundred cases of scoliosis. $\mathcal{F}$ Bone foint Surg 1928 10:724-34.

23 Weinstein SL, Zavala DL, Ponseti IV. Idiopathic scoliosis Long term follow up and prognosis in untreated patients. f Bone foint Surg 1981;63-A:702-12.

24 Gagnon S, Jodoin A, Martin R. Pulmonary function test study and after spinal fusion in young idiopathic scoliosis. Spine 1989;14:486-90

25 Gazioglu K, Goldstein LA, Femi-Pearse D, Yu PN. Pulmonary function in idiopathic scoliosis. Comparative evaluation before and after orthopaedic correction. $\mathcal{F}$ Bone foint Surg 1968;50-A:1391-9.

$26 \mathrm{Lindh} \mathrm{M}$, Bjure J. Lung volumes in scoliosis before and after correction by the Harrington instrumentation method. Acta Orthop Scand 1975;46:934-48.

27 Gucker T. Changes in vital capacity in scoliosis. Preliminary report on effects of treatment. F Bone foint Surg 1962;44A:469-81.

28 Westgate HD, Moe JH. Pulmonary function in kyphoscoliosis before and after correction by the Harrington instrumentation method. $\mathcal{f}$ Bone foint Surg 1969;51-A: instrument 46.

29 Upadhyay SS, Ho EKW, Gunawardene WMS, Leong JCY, Hsu LCS. Changes in residual volume relative to vital capacity and total lung capacity after arthrodesis of the spine in patients who have adolescent idiopathic scoliosis. f Bone foint Surg 1993;75-A:46-52.

30 Godfrey S. Respiratory and cardiovascular consequence of scoliosis. Respiration 1970;27:67-70.

31 Weber B, Smith JP, Briscoe WA, Friedman SA, King TKC. Pulmonary function in asymptomatic adolescents with
idiopathic scoliosis. Am Rev Respir Dis 1975;111:389-97.

32 Kafer ER. Idiopathic scoliosis. Mechanical properties of the respiratory system and the ventilatory response to carbon respiratory system and the ventilatory resp

33 Gibson GJ, Pride NB, Newsom Davis J, Loh LC. Pulmonary mechanics in patients with respiratory muscle weakness. Am Rev Respir Dis 1977;115:389-95.

34 De Troyer A, Pride NB. The respiratory system in neuromuscular disorders. In: Roussos C, Macklem PT, eds. The thorax New York: Marcel Dekker, 1985:1089-121.

35 Swank SM, Brown JC, Perry RE. Spinal fusion in Duchenne's muscular dystrophy. Spine 1982;7:484-91.

36 Rideau Y, Glorian B, Delaubier A, Tarlé O, Bach J. The treatment of scoliosis in Duchenne muscular dystrophy. Muscle Nerve 1984;7:281-6.

37 Cambridge W, Drennan JC. Scoliosis associated with Duchenne muscular dystrophy. $\mathcal{F}$ Pediatr Orthop 1987;7: 436-40.

38 Vianello A, Bevilacqua M, Salvador V, Cardaioli C, Vincent E. Long-term nasal intermittent positive pressure ventilation in advanced Duchenne's muscular dystrophy. Chest 1994;105:445-8. 